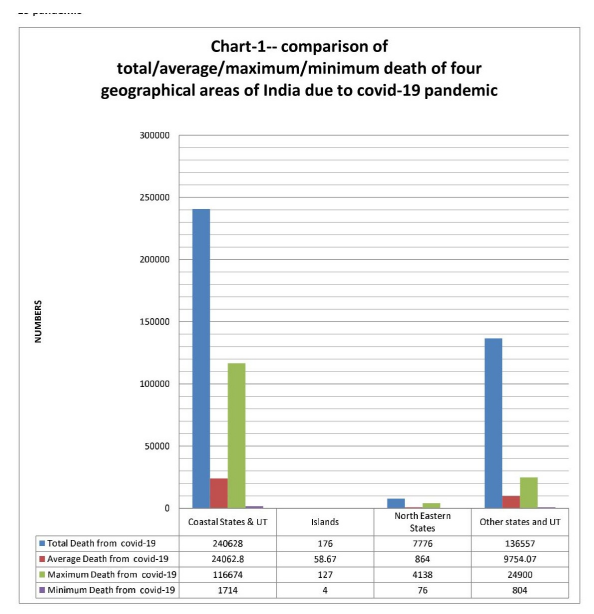

\title{
What impacts have geographical locations on the cases and deaths from COVID-19/SARS-CoV-2 pandemic in 36 states and union territories of India:- observational analysis in India - V2
}

DR PIYUSH KUMAR ${ }^{1}$

1 B. R. Ambedkar Bihar University

Funding: The author(s) received no specific funding for this work.

Potential competing interests: The author(s) declared that no potential competing interests exist.

\section{Abstract}

Background: Curiosity and need are the major forces driving invention and discoveries. The covid-19 pandemic is said to be originated from Wuhan of Hubei province in china. This statement has raised many questions and doubts about origin and spread of disease and the controversy is still going on. The geographical location of Wuhan in relation to sea is of significant value in relation to covid-19 pandemic as observed in this research. The city of Wuhan is located on both banks of the Changjiang (the Great River, a.k.a the Yangtze River) about six hundred miles upstream from Shanghai and the Pacific Ocean. It is about four hundred miles upstream from Nanjing. Its location is supremely strategic, being where the Hanshui (Han River) joins the Changjiang. The Wuhan Huanan Seafood Wholesale Market was in news and highlighted by several media and news agency as probable source of origin of covid-19. The Huanan Seafood Market located in Wuhan is a live animal and seafood market in Jianghan District, Wuhan City, and the capital of Hubei Province in Central China.

Objective: This continuous observational research analysis aimed to assess the impact of 
geographical locations particularly coastal influence on the total/average/maximum/minimum confirmed cases and deaths from COVID-19/SARS-CoV-2 pandemic in 36 states and union territories of India, during COVID-19 pandemic from the beginning of pandemic cases in January 2020 in India with special focus on coastal states and union territories of India. The coast is also known popularly as the coastline or seashore is the area where land meets the sea or ocean, or as a line that forms the boundary between the land and the ocean. The term coastal state and union territories is used to refer to a state where interactions of sea and land of states occur. The study also aims to find safest geographical location in covid-19 pandemic.

Methods: This is a novel cross-sectional mixed (quantitative and Qualitative) continuous observational research study. The information on the number of cases and deaths due to COVID-19 pandemic in 36 states and union territories of India is obtained from Health Department, Ministry of Health and Family Welfare (MoHFW), Government of India, and data were matched and analyzed from online websites as well. The impact of geographical locations on the total/average/maximum/minimum confirmed cases and deaths from COVID-19/SARS-CoV-2 pandemic in 36 states and union territories of India was analyzed with Microsoft office and with more data collection stata 15.1 for windows (64bit) will be used when required with Microsoft office in next version-3 of article (for bigger analysis) for epidemiological comparison by calculating incidence, prevalence, mortality rate and other indicators. The study for global correlation of this research is also under process by the author. For the purpose of research India is divided into four geographical areas , 1 Coastal states and union territories (total ten in numbers), 2 Island groups (three in numbers), 3 north eastern states and east area i.e. Laddakh 4 other states and union territories having plain areas (14 in numbers). Results: The findings showed that total numbers of death from covid-19 is highest in coastal states and union territories with a count of 323674 since beginning of the pandemic whereas the islands group reported the lowest total 184 numbers of deaths from covid-19 as on 05 Jan 2022, 08:00 IST (GMT+5:30) . The average death from covid-19 is highest in coastal states and union territories group with a count of 32367.4 followed by other states and union territories group with a count of 10431.21429. The islands group reported the lowest average numbers of death from covid-19 with a count of 61.33. A similar trend was found for numbers of confirmed cases with coastal states on top having largest number of covid-19 cases. In this version 2 the prevalence rates are also calculated per $\mathbf{1 0 0 0 0 0 .}$

Conclusions: The research observation found that coastal states and union territories of India have larger number of daily cases of COVID-19 and mortality 867 per 100000 as compared to other geographical locations of the country. The observation also found that islands have least number of cases and deaths 115 per 100000 due to covid-19 pandemic. This study also gives rise to hypothesis that coastal locations are at greater risk of covid-19 infection and mortality whereas islands are safest places in covid-19 pandemics.

Keywords: coastal states, COVID 19, Mortality, confirmed cases, union territories, geographical impact, 
Background: Curiosity and need are the major forces driving invention and discoveries. The covid-19 pandemic said to be originated from Wuhan of Hubei province in china. This has raised many questions and doubts about origin and spread of disease and the controversy is still going on. The First globally announced human case of this global pandemic was reported from Wuhan city of China in December 2019. The first case of SARS-CoV-2 in India was discovered in January 2020 [1].

The geographical location of Wuhan in relation to sea is of significant value in relation to covid-19 pandemic as observed in this research. The city of Wuhan is located on both banks of the Changjiang (the Great River, a.k.a the Yangtze River) about six hundred miles upstream from Shanghai and the Pacific Ocean. It is about four hundred miles upstream from Nanjing. Its location is supremely strategic, being where the Hanshui (Han River) joins the Changjiang [2]. The Wuhan Huanan Seafood Wholesale Market was in news and highlighted by several media and news agency as probable source of origin of covid19. The Huanan Seafood Market located in Wuhan was a live animal and seafood market in Jianghan District, Wuhan City, and the capital of Hubei Province in Central China [3]. The Severe Acute Respiratory Syndrome Coronavirus 2 (SARS-CoV-2) also known as COVID-19 pandemic, first case reported in Wuhan, China which had spread worldwide and causing morbidity, mortality as well as severe economic losses. The SARS-CoV-2/ Covid -19 pandemic are still not over globally as well as in Indian states and union territories.

The current healthcare system is overburdened more with this new diseases added with Mucormycosis [4] as well as previous NCD (non communicable diseases) \& CD (communicable diseases) [5]. The First human case of this global pandemic was reported from Wuhan city of China in December 2019. The first case ofcovid-19 in India was found in January 2020 on January 27, 2020, a 20 yr old female presented to the Emergency Department in General Hospital, Thrissur, Kerala, with a one-day history of dry cough and sore throat later confirmed to be covid-19 case. This first case was from the coastal group of states and union territories as per division of states and union territories for this study [6].

As of January 06, 2022, 10:52 GMT, covid-19 has involved 222 countries and has infected $\mathbf{2 9 8 , 4 0 9 , 9 1 1 ~ p e o p l e ~ w i t h ~ a ~ m o r t a l i t y ~ o f ~} \mathbf{5 , 4 8 4 , 2 8 6}$ deaths [7]. The SARS-CoV-2/ Covid -19 coronavirus belongs to the big family of coronavirus. Usually they cause respiratory infection in Homo sapiens sapiens like other respiratory viruses such as rhinoviruses/ human respiratory syncytial virus/ parainfluenza viruses/ adenoviruses/influenza A \& B viruses / enteroviruses / herpes simplex viruses/ human metapneumoviruses etc. The history of SARS-2002/2003 may be older than south china outbreak which begin with 8096 recognized cases in 28 countries \& added to this $90 \%$ of cases occurred in China and Hongkong. Today's world is moving very fast or we can say the host factors (human beings) related spread have exaggerated the pandemic added with various climatic changes. Previously the natural reservoir of SARS-CoV appeared to be horseshoe bat. The 2002-2003 outbreaks thought to be originated due to human contacts with Covid infected domestic animals. The fact of significance is that in 2002-2003 as well as in 2019-2020-2021 most cases spread from human to human and there are multiple ways of spread particularly respiratory droplets. The 2002 outbreak ceased in 2003 but 2019 outbreak is still going on and 
global fast modern transportation methods is one of the most important factors. The super spreaders may remain symptomless while spreading the disease to other human beings. The incubation period is 1-14 days range [8].

The lockdown strategies have been enforced all over the world in order to prevent the COVID-19 infection from spreading even further. The lockdown have deleterious effect on various health programmes, increases domestic violence as well as creates economic problems in poor states and countries $[9,10,11]$ On comparing the geographical locations and number of cases and deaths due to covid-19 this research study found coastal regions more favorable for the spread of covid-19 infections. It may be due to coastal climatic conditions, consumption of sea foods etc but the low rates of covid-19 cases and death in Islands who are also having access to sea foods points that sea food cannot be blamed for covid-19 Vaccines are known to significantly prevent a COVID-19 infection and decrease morbidity-mortality but there are several factors and hindrance in running the vaccination programme in India and other countries such as frequent change and unavailability of vaccines, guidelines, policies, interdisciplinary conflicts of medical sciences, mistrust, evil propaganda over Government data, lack of communication and health promotion in rural areas of India [12].

The present study aimed to investigate the impact of geographical locations on the total /average/maximum/ minimum confirmed cases and deaths from COVID-19/SARS-CoV-2 pandemic in $\mathbf{3 6}$ states and union territories of India. The states and union territories of India are divided into different groups as per geographical locations of the states and union territories to understand the impact of covid-19 in states having Wuhan like coastal areas. Impact of climate change on the coastal states environment is of serious concern to India. The climate change is reflected in sea surface temperature and characteristics of tropical storms. The Frequency and intensity of cyclonic storms are increasing every year. Floods associated with heavy rainfall often paralyses and disrupts life in the coastal states and union territories. The climates of the Coastal states are mild, with hot summers and cool winters with few hard freezes. Precipitation is high, particularly along the coast; India's more than 7,500 square kilometers of coastline [13] are at high risk for impacts of climate change related to sea-level rise. Beyond displacement and migration along the eastern coast, sea-level rise and flooding lead to increased relocation in major coastal states.

Objective: My research aimed to assess the impact of geographical locations particularly coastal influence on the total/average/maximum/minimum confirmed cases and deaths from COVID-19/SARSCoV-2 pandemic in 36 states and union territories of India, during COVID-19 pandemic from the beginning of pandemic cases in January 2020 in India with special focus on coastal states and union territories of India. The coast is also known popularly as the coastline or seashore is the area where land meets the sea or ocean, or as a line that forms the boundary between the land and the ocean. The term coastal state and union territories is used to refer to a state where interactions of sea and land of states occur. The study also aims to find safest geographical location in covid-19 pandemic. 


\section{Materials and methods: This is a novel cross-sectional mixed (quantitative and Qualitative)} continuous observational research study. The information on the number of cases and deaths due to COVID-19 pandemic in 36 states and union territories of India was obtained from Health Department, Ministry of Health and Family Welfare (MoHFW), Government of India, and data were matched and analyzed from online websites as well. The impact of geographical locations on the total/average/maximum/minimum confirmed cases and deaths from COVID-19/SARS-CoV-2 pandemic in 36 states and union territories of India was analyzed with Microsoft office and stata 15.1 for windows (64bit) will be used with Microsoft office in next version-3 of article if required for epidemiological comparison by calculating incidence, prevalence, mortality rate and other indicators. The study for global correlation of this research is also under process by the author. For the purpose of research India is divided into four geographical areas , 1 Coastal states and union territories (total ten in numbers), 2 Island groups (three in numbers), 3 north eastern states and east area i.e. Laddakh 4 other states and union territories having plain areas (14 in numbers). The present observational study was conducted by the author during the period of December 2019 to 05 January 2022. The data on the trends in the incidence, prevalence and mortality due to COVID-19 outbreak in India were collected on daily basis from Health Department, as well as Ministry of Health and Family Welfare, Government of India also matched with online sources available in Google search and other database. The daily reports on COVID-19 published by the Health Department, as well as Ministry of Health and Family Welfare, Government of India through website, twitter etc. were care-fully reviewed and data were collected for analysis. Data of all the states and union territories of India have been collected and analyzed as well as calculation for incidence, prevalence and mortality will be done in version 2 of study. The data and calculations presented as table (see table 1, 2, 3,4,5,6, 7, 8, and chart 1, 2, 3, 4) and chart in this article.

The geographical division I considered is states and union territories having sea-coast, island into one group, north eastern states having geographical similarities in one group and states having plain areas in one group as other states and union territories. The total number of cases and deaths in different geographical groups were added and mean was calculated separately for the four geographical divisions. The collected data were properly recorded and analyzed for the different geographical locations because the pandemic has been changing numbers daily. I analyzed the impact of geographical locations on the total/average/maximum/minimum confirmed cases and deaths from COVID-19/SARS-CoV-2 pandemic in 36 states and union territories of India since the beginning of the pandemic till 19/06/2021.

\section{Source of Data: The key data source is as mentioned below}

\section{1. https://www.mygov.in/corona-data/covid19-statewise-status/}

2. https://www.nytimes.com/interactive/2021/world/india-covid-

\section{3. https://main.mohfw.gov.in/}

Statistical analysis: The data for the 36 states and union territories were recorded, calculated and analyzed with Microsoft office in this version 2(in next version 3 stata software will be utilized added with 
Microsoft for analysis), and the output-results were expressed in numbers presented in tables 1,2,3,4,5,6,7,8, AND CHART 1,2,3 and 4. The total/average/maximum/minimum confirmed cases and deaths from COVID-19/SARS-CoV-2 pandemic in 36 states and union territories of India were calculated. The average of total divided by number of states and union territories of respective group was calculated. Results: The total number of laboratory confirmed cases and deaths in coastal states and union territories of India due to covid-2019 pandemic from the beginning of pandemic till 05 Jan 2022, 08:00 IST $($ GMT+5:30)) are presented in Table 1 . The total number of laboratory confirmed cases and deaths in Islands group of India due to covid-2019 pandemic from the beginning of pandemic till 05 Jan 2022, 08:00 IST (GMT+5:30) are presented in Table 2 . The total number of laboratory confirmed cases and deaths in north eastern states and Laddakh of India due to covid-2019 pandemic from the beginning of pandemic till 05 Jan 2022, 08:00 IST (GMT+5:30) are presented in Table 3. The total number of laboratory confirmed cases and deaths in other states and union territories of India due to covid-2019 pandemic from the beginning of pandemic till 05 Jan 2022, 08:00 IST (GMT+5:30) are presented in Table 4.

The impact of the geographical locations on the trends of covid-19 cases and deaths is presented in Tables 5, 6, 7, and 8. The comparison of total/average/maximum/minimum death of four geographical areas of India due to covid-19 pandemic presented in table 5 and chart 1, the findings showed that total numbers of death from covid-19 is highest in coastal states and union territories with a count of 323674 since beginning of the pandemic whereas the islands group reported the lowest total numbers of death count 184 from covid-19. The average death from covid-19 is highest in coastal states and union territories group with a count of 32367.4 followed by other states and union territories group with a count of 10431 . The islands group reported the lowest average numbers of death from covid-19 with a count of 61.33. A similar trend was found for numbers of confirmed cases with coastal states on top having largest number of covid-19 cases as shown in table number 6 and chart 2 .

The comparison of total/average/maximum/minimum death per 100000 of four geographical areas of India due to covid-19 pandemic presented in table 7 and chart 3, the findings showed that total numbers of death per 100000 from covid-19 is highest in coastal states and union territories with a count of $867 / 100000$ since beginning of the pandemic whereas the islands group reported the lowest total numbers of death count 115/100000 from covid-19.

A similar trend was found for numbers of confirmed cases per 100000 with coastal states on top having largest number of covid-19 cases as shown in table number 8 and chart 4 .

Table 1- total deaths and confirmed cases from covid-19 in coastal states and union territories of India 


\begin{tabular}{|c|c|c|c|}
\hline Serial no. & $\begin{array}{l}\text { Coastal States \& } \\
\text { UT }\end{array}$ & $\begin{array}{l}\text { Total Death from covid- } \\
19\end{array}$ & $\begin{array}{l}\text { Total confirmed cases of covid- } \\
19\end{array}$ \\
\hline 1 & Maharashtra & 141573 & 6730494 \\
\hline 2 & Karnataka & 38355 & 3013326 \\
\hline 3 & Kerala & 48637 & 5258614 \\
\hline 4 & Tamil Nadu & 36805 & 2755587 \\
\hline 5 & Andhra Pradesh & 14499 & 2077942 \\
\hline 6 & West Bengal & 19810 & 1664301 \\
\hline 7 & Odisha & 8464 & 1056660 \\
\hline 8 & Gujarat & 10125 & 837293 \\
\hline 9 & Goa & 3525 & 182793 \\
\hline 10 & Puducherry & 1881 & 129619 \\
\hline
\end{tabular}

Table 2- total deaths and confirmed cases from covid-19 in Islands of India

\begin{tabular}{|l|l|l|l|}
\hline Serial no. & Islands & $\begin{array}{l}\text { Total } \\
\text { Death }\end{array}$ & $\begin{array}{l}\text { Total confirmed cases of covid- } \\
19\end{array}$ \\
\hline 1 & Andaman \& Nicobar & 129 & 7799 \\
\hline 2 & Lakshadweep & 51 & 10419 \\
\hline 3 & Dadra and Nagar Haveli and Daman and Diu & 4 & 10701 \\
\hline
\end{tabular}

Table 3- total deaths and confirmed cases from covid-19 in North eastern states and Laddakh of India

\begin{tabular}{|l|l|l|l}
\hline Serial no. & $\begin{array}{l}\text { North Eastern } \\
\text { States }\end{array}$ & $\begin{array}{l}\text { Total } \\
\text { Death }\end{array}$ & $\begin{array}{l}\text { Total confirmed cases of covid- } \\
19\end{array}$ \\
\hline 1 & Mizoram & 553 & 142691 \\
\hline 2 & Sikkim & 409 & 32530 \\
\hline 3 & Laddakh & 220 & 22321 \\
\hline 4 & Nagaland & 702 & 32210 \\
\hline 5 & Arunachal Pradesh & 282 & 55375 \\
\hline 6 & Meghalaya & 1485 & 84881 \\
\hline 7 & Tripura & 829 & 85214 \\
\hline 8 & Manipur & 2006 & 125878 \\
\hline 9 & Assam & 6170 & 621897 \\
\hline
\end{tabular}

Table 4- total deaths and confirmed cases from covid-19 in other states and union territories of India 


\begin{tabular}{|l|l|l|l|}
\hline Serial no. & Other states and UT & $\begin{array}{l}\text { Total } \\
\text { Death }\end{array}$ & $\begin{array}{l}\text { Total confirmed cases of covid- } \\
19\end{array}$ \\
\hline 1 & Chandigarh & 1079 & 66264 \\
\hline 2 & Himachal Pradesh & 3879 & 229413 \\
\hline 3 & Jammu and Kashmir & 4530 & 342001 \\
\hline 4 & Uttarakhand & 7420 & 345963 \\
\hline 5 & Jharkhand & 5149 & 357965 \\
\hline 6 & Punjab & 16653 & 606927 \\
\hline 7 & Telangana & 4033 & 684023 \\
\hline 8 & Bihar & 12096 & 728766 \\
\hline 9 & Haryana & 10066 & 776842 \\
\hline 10 & Madhya Pradesh & 10534 & 794769 \\
\hline 11 & Rajasthan & 8965 & 958570 \\
\hline 12 & Chhattisgarh & 13604 & 1010513 \\
\hline 13 & Delhi & 25113 & 1463701 \\
\hline 14 & Uttar Pradesh & 22916 & 1714096 \\
\hline & & & \\
\hline
\end{tabular}

Note: Laddakh, large area of the northern and eastern Kashmir region

Note-COVID-19 INDIA as on: 05 Jan 2022, 08:00 IST (GMT+5:30)

Source of total death and confirmed cases- Ministry of Health and Family Welfare, Government of India

Table-5- comparison of total/average/maximum/minimum death of four geographical areas of India due to covid-19 pandemic

\begin{tabular}{|c|c|c|c|c|}
\hline $\begin{array}{l}\text { Geographical } \\
\text { area }\end{array}$ & $\begin{array}{l}\text { Total Death from } \\
\text { covid-19 }\end{array}$ & $\begin{array}{l}\text { Average Death from } \\
\text { covid-19 }\end{array}$ & $\begin{array}{l}\text { Maximum Death from } \\
\text { covid-19 }\end{array}$ & $\begin{array}{l}\text { Minimum Death from } \\
\text { covid-19 }\end{array}$ \\
\hline $\begin{array}{l}\text { Coastal States \& } \\
\text { UT }\end{array}$ & 323674 & 32367.4 & 141573 & 1881 \\
\hline Islands & 184 & 61.33333333 & 129 & 04 \\
\hline $\begin{array}{l}\text { North Eastern } \\
\text { States }\end{array}$ & 12656 & 1406.222222 & 6170 & 220 \\
\hline $\begin{array}{l}\text { Other states and } \\
\text { UT }\end{array}$ & 146037 & 10431.21429 & 25113 & 1079 \\
\hline
\end{tabular}

Table-6- comparison of total/average/maximum/minimum confirmed cases of four geographical areas of India due to covid-19 pandemic 


\begin{tabular}{|c|c|c|c|c|}
\hline $\begin{array}{l}\text { Geographical } \\
\text { area }\end{array}$ & $\begin{array}{l}\text { Total confirmed cases } \\
\text { of covid-19 }\end{array}$ & $\begin{array}{l}\text { Average confirmed cases } \\
\text { of covid-19 }\end{array}$ & $\begin{array}{l}\text { Maximum confirmed cases } \\
\text { of covid-19 }\end{array}$ & $\begin{array}{l}\text { Minimum confirmed cases } \\
\text { of covid-19 }\end{array}$ \\
\hline $\begin{array}{l}\text { Coastal States } \\
\& \text { UT }\end{array}$ & 23706629 & 2370662.9 & 6730494 & 129619 \\
\hline Islands & 28919 & 9639.666667 & 10701 & 7799 \\
\hline $\begin{array}{l}\text { North Eastern } \\
\text { States }\end{array}$ & 1202997 & 133666.3333 & 621897 & 22321 \\
\hline $\begin{array}{l}\text { Other states } \\
\text { and UT }\end{array}$ & 10079813 & 719986.6429 & 1714096 & 66264 \\
\hline
\end{tabular}

Chart-1- Comparison of total/average/maximum/minimum death of four geographical areas of India due to covid-19 pandemic 


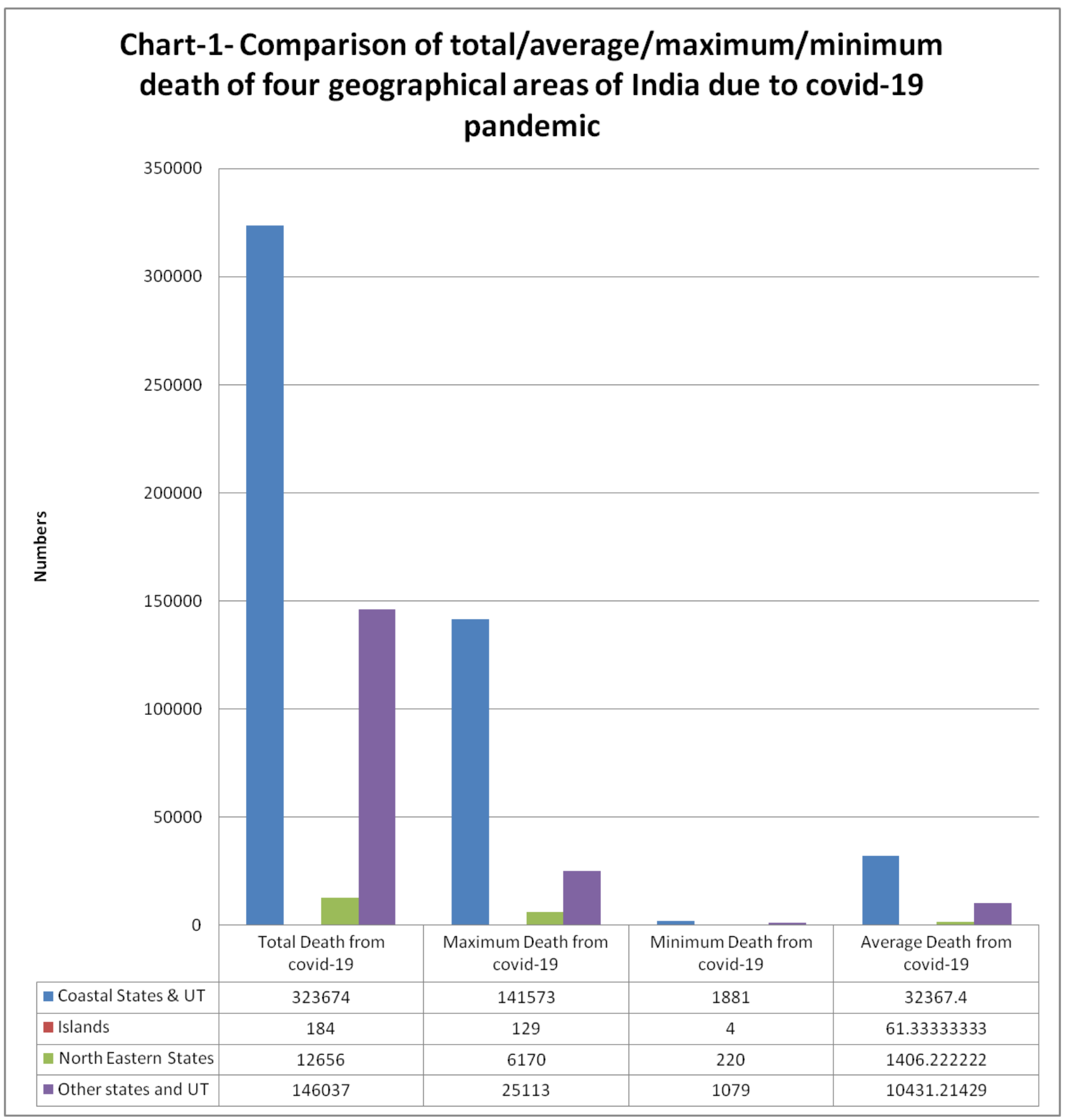

Chart-2- comparison of total/average/maximum/minimum confirmed cases of four geographical areas of India due to covid-19 pandemic 


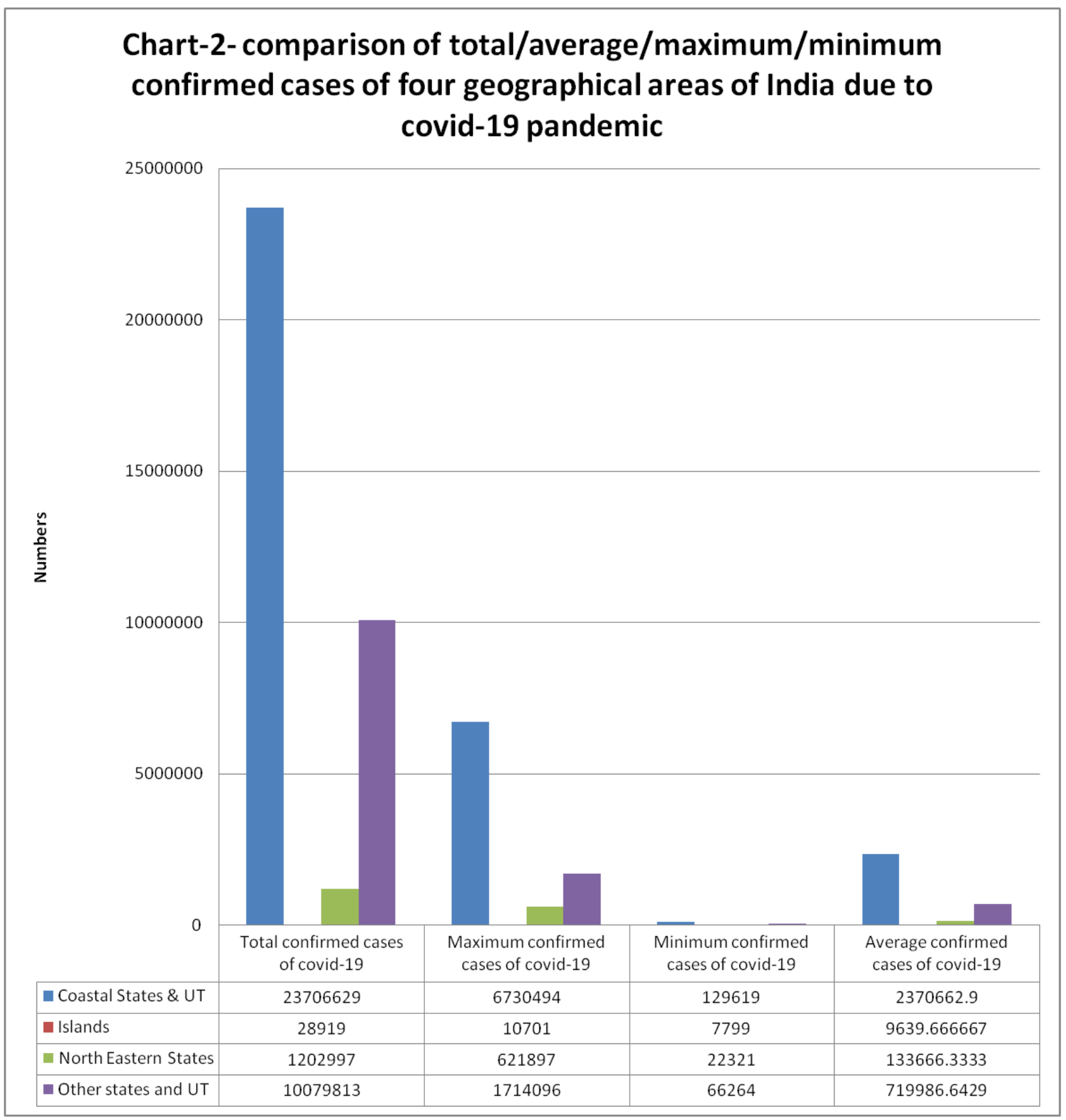

Table 7- comparison of total/average/maximum/minimum death per 100000 of four geographical areas of India due to covid-19 pandemic 


\begin{tabular}{|c|c|c|c|c|}
\hline $\begin{array}{l}\text { Geographical } \\
\text { Area }\end{array}$ & $\begin{array}{l}\text { Total Death per } \\
100000 \text { from covid-19 }\end{array}$ & $\begin{array}{l}\text { Maximum total Death per } \\
100000 \text { from covid-19 }\end{array}$ & $\begin{array}{l}\text { Minimum total Death per } \\
100000 \text { from covid-19 }\end{array}$ & $\begin{array}{l}\text { Average total Death per } \\
100000 \text { from covid-19 }\end{array}$ \\
\hline $\begin{array}{l}\text { Coastal } \\
\text { States \& UT }\end{array}$ & 867 & 242 & 17 & 86.7 \\
\hline Islands & 115 & 79 & 2 & 38.33333333 \\
\hline $\begin{array}{l}\text { North } \\
\text { Eastern } \\
\text { States }\end{array}$ & 423 & 80 & 20 & 47 \\
\hline $\begin{array}{l}\text { Other states } \\
\text { and UT }\end{array}$ & 652 & 150 & 11 & 46.57142857 \\
\hline Geographical & Total cases per & Maximum total cases per & Minimum total cases per & Average total cases per \\
\hline Area & 100000 from covid-19 & 100000 from covid-19 & 100000 from covid-19 & 100000 from covid-19 \\
\hline $\begin{array}{l}\text { Coastal } \\
\text { States \& UT }\end{array}$ & 63333 & 15741 & 1385 & 6333.3 \\
\hline Islands & 22608 & 16160 & 2049 & 7536 \\
\hline $\begin{array}{l}\text { North } \\
\text { Eastern } \\
\text { States }\end{array}$ & 44121 & 13005 & 1628 & 4902.333333 \\
\hline $\begin{array}{l}\text { Other states } \\
\text { and UT }\end{array}$ & 40854 & 8719 & 700 & 2918.142857 \\
\hline
\end{tabular}

The average calculation shows that majority of these coronavirus confirmed cases, were reported during the period of observation from coastal states and union territories of India followed by other states and union territories, north eastern states and islands respectively. The maximum confirmed cases, were reported during the period of observation from coastal states and union territories of India followed by other states and union territories, north eastern states and islands respectively (Table 6). The minimum confirmed cases, were reported during the period of observation from islands group of India (Table 6).

Chart 3 - Comparison of total/average/maximum/minimum death per 100000 of four geographical areas of India due to covid-19 pandemic 


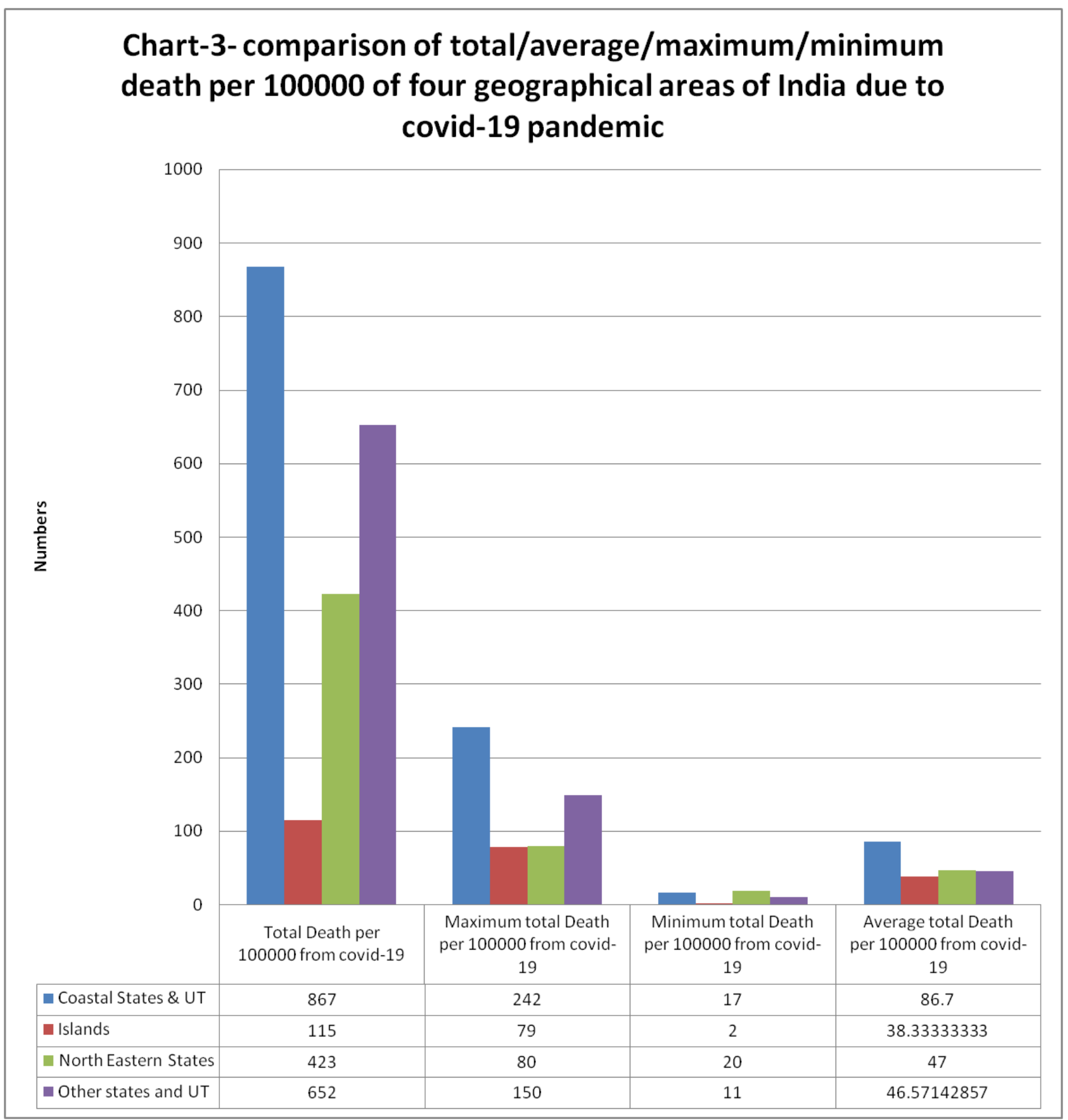

Chart - 4 - comparison of total/average/maximum/minimum confirmed cases per 100000 of four geographical areas of India due to covid-19 pandemic 


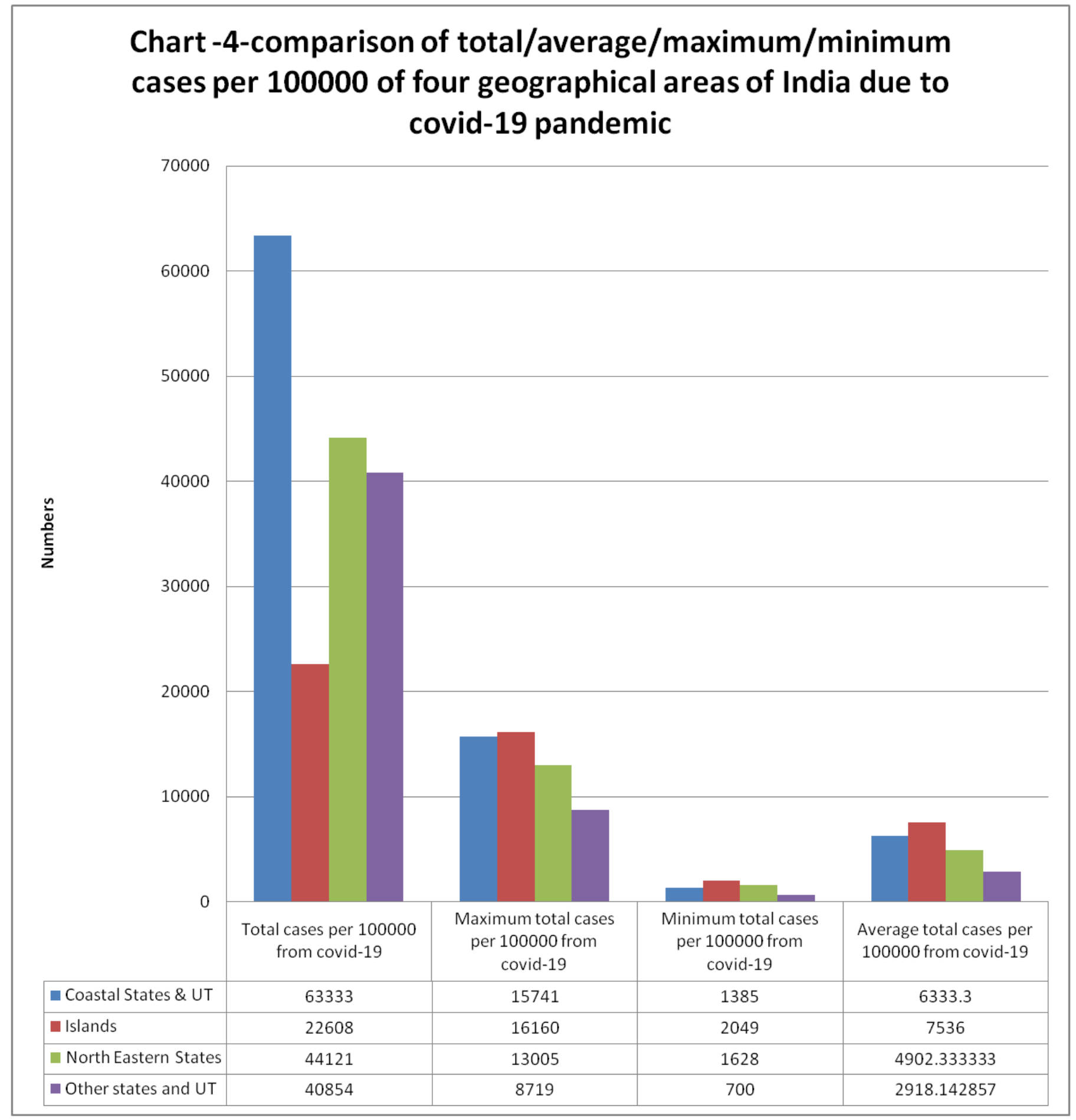

The average calculation shows that majority of these coronavirus confirmed cases per100000, were reported during the period of observation from islands, followed by coastal states and union territories of India, north eastern states and other states and union territories, respectively. The maximum confirmed cases per 100000, were reported during the period of observation from islands, followed by coastal states and union territories of India, north eastern states and other states and union territories, respectively (Table 8). The minimum confirmed cases per 100000, were reported during the period of observation from other states and union territories group of India (Table 8).

Regarding the impact of geographical location on the mortality of the COVID-19 outbreak in India, I found 
that during the period of observation majority of these coronavirus confirmed deaths, were reported from coastal states and union territories of India followed by other states and union territories, north eastern states and islands respectively (Table5). The maximum confirmed deaths from covid-19, were reported during the period of observation from coastal states and union territories of India followed by other states and union territories, north eastern states and islands respectively (Table 5). The minimum confirmed deaths, were reported during the period of observation from islands group of India (Table 5). Regarding the impact of geographical location on the mortality per 100000 of the COVID-19 outbreak in India, I found that during the period of observation majority of these coronavirus confirmed deaths per 100000, were reported from coastal states and union territories of India followed by other states and union territories, north eastern states and islands respectively (Table7). The maximum confirmed deaths per 100000 from covid-19, were reported during the period of observation from coastal states and union territories of India followed by other states and union territories, north eastern states and islands respectively (Table 7). The average total Death per 100000 from covid-19 also followed a similar trend. The minimum confirmed deaths per 100000, were reported during the period of observation from islands group of India (Table 7).

Discussion: The COVID-19 pandemic is a subject of concern globally and major public health problem. The pandemic infected millions of people worldwide. The idea of association of geographical location with covid-19 came to authors mind while the author was posted on Adhaura hills (2020) primary health centre of Bihar, India, where he observed the cases are very less as compared to plain land of Kaimur district where Adhaura hills are located. Adhaura primary health centre is situated at a height of 2000 feet from the sea level on Kaimur plateau at a Distance of 58 Kilometers from Bhabua. The association of covid-19 with coastal areas is very significant as seen in case of Wuhan, china and various coastal states and union territories of India. The coastal locations have shown more infections and deaths due to covid-19 in India as observed in this study. The covid-19 had originated in the coastal city of Wuhan and this observational research from India indicates that coastal states and union territories are most affected by covid-19 which indicates a deep correlation between the covid19 and coastal regions. For keeping this pandemic under control we must control the rate of growth and mortality in coastal regions. In this study, I observed the impact of geographical locations on the outbreak, cases and deaths due to novel coronavirus SARS-COV-2 in India. I observed that there was significant growth in the mean number of confirmed cases and mean mortality due to COVID-19 in coastal states and union territories of India compared to other geographically located states and union territories of India.

The islands groups in India are observed to be the safest place and having minimum numbers of mortality per 100000 due to covid-19 pandemic.

Through this article I recommend that along with other public health analysis and modeling, geographical analysis of the facts related to covid-19 should be done by world Health Organization and related highly esteemed and accredited bodies to find out cause of origin of covid-19 and ways to prevent the SARS-CoV-2 infection from spreading to a large section of population causing increased morbidity and 
mortality as well as overburden on the health system. The author of this article is from LMICs having very poor resources and cannot bear the cost of such research as it will require lots of movement to different areas and research materials but agree to share ideas if any researcher or organization needs. The author is hopeful that this geographical analysis will help international organization to find out some more details on covid-19. The author also hopes to find out exact origin of covid-19 with the facts he have observed in this research study. The study also demonstrates evidence that there is strong linkage with coastal region of India and covid-19 cases and deaths and added to this Wuhan of china have also a coastal background. This study will also help environmentalists to focus on other causes related to coastal areas contributing to excess mortality in coastal states and regions of India.

My study observation showed that the coastal regions of India are most affected from covid19 pandemic. The concept of origin from bat, seafood etc is theoretically very attractive but till today the exact origin of covid-19 is still a matter of debate. It is quite possible that previous strains of 2002 etc after several mutations have emerged as novel coronavirus strain in 2019 in china and the climatic conditions found in coastal areas have acted as catalyst to this process.

My study findings support hypothesis that the number of cases and deaths increases in coastal regions and islands are safest and least likely to be affected from covid-19.I have done this study in a different way and this study can help international organizations in controlling the COVID-19 pandemic as well as finding out origin of novel coronavirus .

Study strengths and limitations: This is the first article in the literature, to my knowledge, that has investigated the impact of geographical locations on the cases and deaths from COVID19/SARS-CoV-2 pandemic in 36 states and union territories of India. During the COVID-19 pandemic, to date, several mathematical modeling-based public health reviews/articles have been published to hypothesize the impact of a lockdown on the prevalence of COVID-19 cases. This is the first study, which analyzed the impact of geographical locations on the cases and deaths from COVID-19/SARSCoV-2 pandemic in 36 states and union territories of India. One of the peculiar strength is that the study data were gathered using reliable accredited sources including Government Health Department. I have analyzed the linkage between the geographical location and covid-19 starting from Wuhan china, which are

exceptional and totally new my idea to determine the cases and mortality trends of a pandemic. A limitation is that I have not calculated the epidemiological indicators taking into account the global population of the different zones of study in world context. As I have told in the next version 3 of this article this limitation will be tried to be removed and more strength will be added with more analytic report using stata software.

Conclusions: My research shows that there is clear impact of geographical locations on the cases and deaths from COVID-19/SARS-CoV-2 pandemic in 36 states and union territories of India. This observational research study is very much significant to assess the mean cases and mean mortality due to novel 
coronavirus SARS-COV 2. Compared to coastal states and union territories other states of India have a lesser number of confirmed cases and deaths due to covid-19 especially islands. More evidence is required and more research is needed to be done to find out all the factors using tree model or some other models. The author is working on this article and this is second version of authors working paper series on this title and topic mentioned on pagel. Kindly go through version 1 for clarity [14].

\section{'Declarations':}

-This version of paper has not been previously published and is not currently under consideration by another journal. The document is Microsoft word with English (United States) language \& 5631 words Total.

- Ethics approval and consent to participate: Not applicable. This study has not involved any human or animals in real or for experiments. The data on the COVID-19 pandemic were taken from the Health Department, and other organizations which are also available online, hence ethical approval was not required.

-Consent for publication: Not applicable

-Availability of data and materials: The data \& materials for study are mentioned in article and available as reference.

-Conflicts of Interest/ Competing Interest: There are no conflicts / competing of interest

- Funding-Self sponsored. No aid taken from individual or agency etc.

- Authors' contributions: The whole work is solely done by the Author - Dr Piyush Kumar, M.B.B.S., E.M.O.C., P.G.D.P.H.M., -Senior General Medical Officer- Bihar Health Services- Health DepartmentGovernment of Bihar, India.

- Acknowledgements- I am thankful to Advocate Anupama my wife and daughters Aathmika-Atheeva for cooperation.

- Author information: The author is currently working as Senior General Medical Officer for the government of Bihar.

-Financial Support \& sponsorship: Nil

\section{-Author contact information}

1 Department of Health, Government of Bihar, MOBILE - +919955301119/+917677833752,

Email drpiyush003@gmail.com

\section{References}

1. Kumar, Piyush and Kumar, Piyush, What Are the Factors Responsible for Increase in SARS-CoV-2/COVID19 Pandemic Related Cases and Death in India in 2021? How Does Environmental, Host \& Agent Factors of Epidemiological Triad Do Influence \& Can Be Utilised to Manage Ongoing Pandemic Cases and Deaths? (April 25, 2021). Available at SSRN: https://ssrn.com/abstract=3833788 or http://dx.doi.org/10.2139/ssrn.3833788

2. Britannica, available at- https://www.britannica.com/place/Wuhan, visited on-19/06/2021

3. The Guardian, available at- https://www.theguardian.com/world/2021/jan/31/who-wuhan-market-covid- 
19, visited on-19/06/2021

4. Kumar, P. (2021, May 26). How to understand and manage Mucormycosis infections during Covid-19/ SARS-CoV-2/ novel coronavirus pandemic era in India \& developing countries?. https://doi.org/10.31219/osf.io/j3r7b

5. Kumar, Piyush and Kumar, Piyush, What Impact Have SARS-CoV-2/COVID-19 Pandemic Induced Lockdown on the Number of OPD Patients of Diabetes, Hypertension, Stroke (CVA), Acute Heart Disease, Mental IIIness, Epilepsy, Ophthalmic, Dental and Oncology in India During the Lockdown Months (April-May2020)-Observational Research Analysis?. Available at

SSRN: https://ssrn.com/abstract=3884940 or http://dx.doi.org/10.2139/ssrn.3884940

6. Piyush Kumar (2022) What Impacts Have Geographical Locations On The Cases And Deaths From Covid19/SarsCov-2 Pandemic In 36 States And Union Territories Of India:-Observational Analysis In India. J Mari Scie Res Ocean, 5(1): 252-258.

7. Worldometer, available at- https://www.worldometers.info/coronavirus/ visited on-06/01/2022

8. Kumar, P. (2021, April 17). How do we can control SARS-CoV-2/ Covid -19 pandemic through various clinical and public health approaches? What are the agent (Covid-19 virus), host \& environmental factors responsible for continuation \& recurrence of SARS-CoV-2/ Covid -19

pandemic?. https://doi.org/10.31219/osf.io/vdhg3

9. Kumar, Piyush and Kumar, Piyush and Farooqui, Habib Hasan, What is the Impact of Covid-19 Pandemic on the RCH (Reproductive and Child Health) Programme in Rajasthan, Because of Nationwide Lockdown (April 2020 to June 2020)?. Available at

SSRN: https://ssrn.com/abstract=3914646 or http://dx.doi.org/10.2139/ssrn.3914646

10. Kumar, Piyush and Kumar, Piyush, What Impact Have SARS-CoV-2/COVID-19 Pandemic on Domestic Violence against Women in India across Different States and Union Territories from the Beginning of Lockdown Due to COVID-19 Pandemic in March 2020 Till 20Th September 2020? How COVID-19 Pandemic Induced Lockdown Influence Mental Health of Women in India? (April 15, 2021). Available at SSRN: https://ssrn.com/abstract=3826837 or http://dx.doi.org/10.2139/ssrn.3826837

11. Kumar, Piyush and Kumar, Piyush, What Impact Has Lockdown on SARS-CoV-2/COVID-19 Incidence, Prevalence and Mortality During Second Wave of Pandemic in 2021: Observational Analysis of Bihar (6/20/2021). Available at

SSRN: https://ssrn.com/abstract=3871321 or http://dx.doi.org/10.2139/ssrn.3871321

12. Kumar, P. (2021, June 4). Vaccination drive could be affected by frequent change in vaccines, guidelines, policies, interdisciplinary conflicts of medical sciences, mistrust, evil propaganda over Government data, lack of communication \& health promotion in rural areas of India. https://doi.org/10.31219/osf.io/pc9uw

13. Climate Change, Displacement, and Managed Retreat in Coastal India, available at https://www.migrationpolicy.org/article/climate-change-displacement-managed-retreat-india

14. https://assets.researchsquare.com/files/rs-640243/v1/b6bf1f46-0447-49e3-aff5-9f47c0550f06.pdf? 
$\mathrm{c}=1631884907$ Dr Piyush Kumar. What impacts have geographical locations on the cases and deaths from COVID-19/SARS-CoV-2 pandemic in 36 states and union territories of India:-observational analysis in India, 21 June 2021, PREPRINT (Version 1) available at Research Square [https://doi.org/10.21203/rs.3.rs$640243 / v 1]$ 